\title{
Analytical investigation of pile-soil interaction in sand under axial and lateral loads
}

\author{
Ahmed Abdel-Mohti • Yasser Khodair
}

Received: 3 September 2013/ Accepted: 17 March 2014/Published online: 17 April 2014

(C) The Author(s) 2014. This article is published with open access at Springerlink.com

\begin{abstract}
This paper presents a numerical study of pilesoil interaction due to application of axial and lateral loads to piles in sand. The pile-soil interaction was analyzed using the finite difference (FD) software LPILE and two finite element (FE) software. The three-dimensional (3D) FE models of pile-soil interaction have been created using Abaqus/Cae and SAP2000. Various types of soft soil were studied, such as loose, medium, and dense sand. A lateral displacement of $2 \mathrm{~cm}$ was applied to the top of the pile while maintaining a zero slope in a guided fixation. A combined lateral and axial load of $300 \mathrm{kN}$ was also studied. The paper compared between the bending moments and lateral displacements along the depth of the pile obtained from the FD solutions and FE analyses. A parametric study was conducted to study the effect of crucial design parameters such as the modulus of elasticity of soil and the number of nonlinear soil springs that can be used to model the soil. A good agreement between the results obtained by the FE models and the FD solution was observed. Also, the FE models were capable of predicting the pile-soil interaction for all types of soft soil.
\end{abstract}

Keywords Pile $\cdot$ Pile-soil interaction $\cdot$ Pile loads

\footnotetext{
A. Abdel-Mohti

Civil Engineering Department, Ohio Northern University,

525 South Main St., Ada, OH 45810, USA

e-mail: a-abdel-mohti@onu.edu

Y. Khodair ( $\square)$

Department of Civil Engineering and Construction, Bradley

University, 1501 West Bradley Avenue, Peoria, IL 61625, USA

e-mail: ykhodair@bradley.edu
}

\section{Introduction}

The pile foundation is used when it is necessary to transfer the loads from the superstructure and abutment to a stronger soil beneath the weak soil near the ground surface, which is not capable of carrying the loads. The pile foundations are subjected to vertical loads as well as lateral loads. To design piles, it is desired to understand pile-soil interaction. Moreover, it is important to construct flexible abutments with piles to permit longitudinal movement in bridges due to thermal, shrinkage, and creep effects (Dicleli and Albhaisi 2003). The steel H-pile (HP-sections) is the most common type of piles that are used to support the abutment of integral bridges.

The pile-soil interaction is a complex problem. The soil is not isotropic, homogeneous, or linear therefore it is important to account for these complicated characteristics (Dutta and Roy 2001). The interaction between the structure and soil has a potential to affect the behavior of the structure (Abdel-Mohti and Pekcan 2013a, b). It is important to evaluate this pile-soil interaction under the effect of both axial and lateral loads. A number of approaches can be used to analyze piles subjected to a lateral loading such as subgrade reaction approach, elastic approach, and finite element approach. Most engineers prefer the $p-y$ curve method over elastic continuum and finite element analysis methods. In each approach, it may be possible to conduct static or dynamic analysis and also the behavior of pile, soil, or pile-soil interaction may be linear or nonlinear. The $p-y$ approach, Winkler subgrade, models the lateral soil-pile interaction using a set of empirical $p-y$ curves (Hartog 1952). In the subgrade modulus reaction approach (Reese and Matlock 1956; Georgiadis and Butterfield 1982; Sawant et al. 1996), the pile is modeled as an elastic beam while the continuum of 
Fig. 1 Soil property inputs for medium sand soil in the finite difference (FD) LPILE model

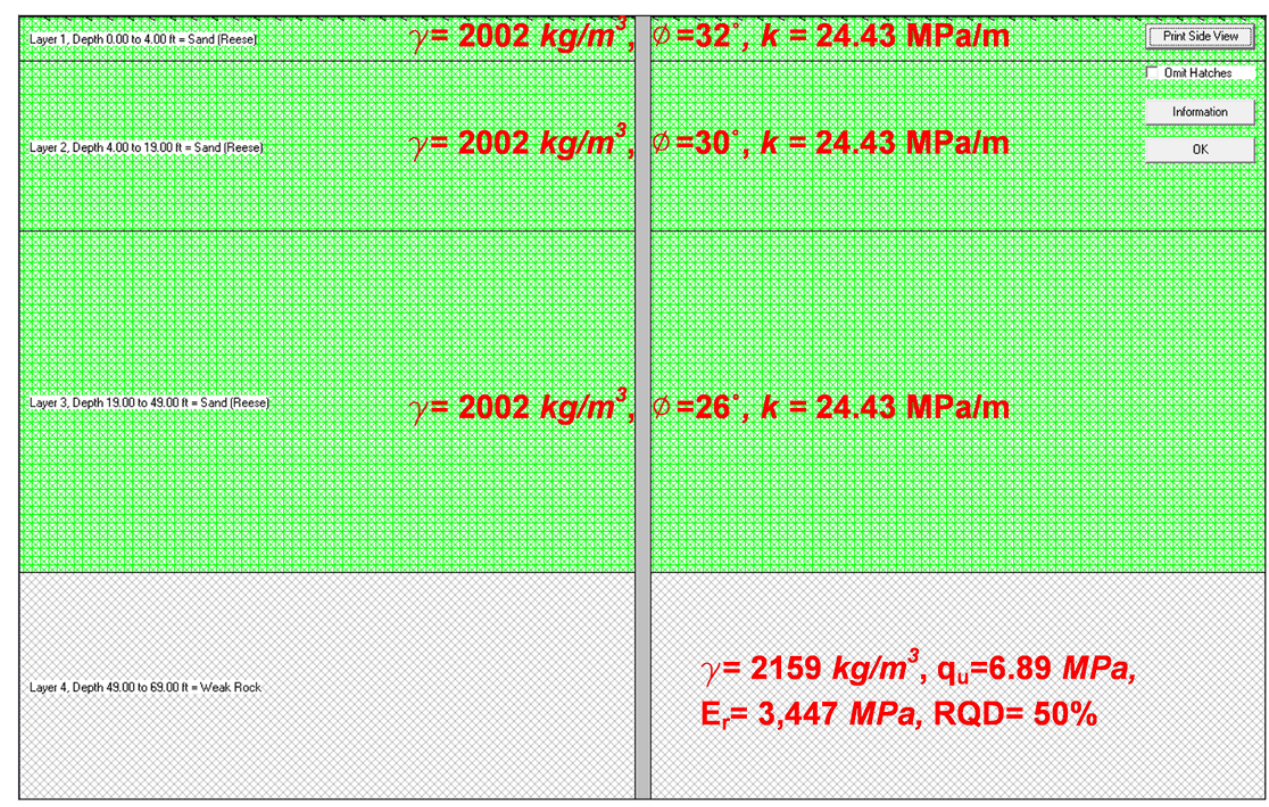

the soil is ignored as the soil is modeled using a series of independent springs having constant stiffness. In spite of the simplicity of this method, it can provide reasonably accurate results. Other approaches include the elastic continuum approach (Spillers and Stoll 1964; Poulos 1971; Banerjee and Davies 1978) and the finite element method. In the elastic approach, the soil is assumed as an elastic continuum. Recently, numerical methods have gained momentum; therefore, a number of researchers used linear and nonlinear finite element analysis to study the pile-soil interaction (Yegian and Wright 1973; Desai 1974; Desai and Abel 1974; Desai and Appel 1976; Kuhlemeyer 1979; Desai et al. 1981; Zaman et al. 1993; Narsimha Rao and Ramkrishna 1996; Bransby and Springman 1999; Ng and Zhang 2001; Sawant and Dewaikar 2001; Krishnamoorthy and Anil 2003; Krishnamoorthy and Nitin 2005; Dewaikar et al. 2007; Zhang 2009; Chore et al. 2010; Muqtadir and Desai 1986; Pressley and Poulos 1986; Brown and Shie 1990a, b, 1991; Trochanis et al. 1991; Kimura et al. 1995; Wakai et al. 1999; Pan et al. 2002). The finite element approach has a capability to deal with any configurations of structures and soil. It was concluded that finite element analysis can be a reliable tool to predict the pile-soil interaction under the effect of lateral load since it can account for the soil mass and the nonlinear nature of pilesoil interaction. It is recommended to orientate the pile for bending about the major axis to improve the displacement capacity of the bridge under low-cycle fatigue while it is recommended to change the orientation of the pile for bending about minor axis if the flexural capacity of the abutment governs the displacement capacity of the bridge (Dicleli and Albhaisi 2003).
The effect of various parameters, such as profiles of soil layers, pile length, and soil layer properties has been investigated (Avaei et al. 2008; Davisson and Gill 1963; Lee and Karunaratne 1987; Reese et al. 1981). LPILE program, developed by Ensoft, uses a method that assumes

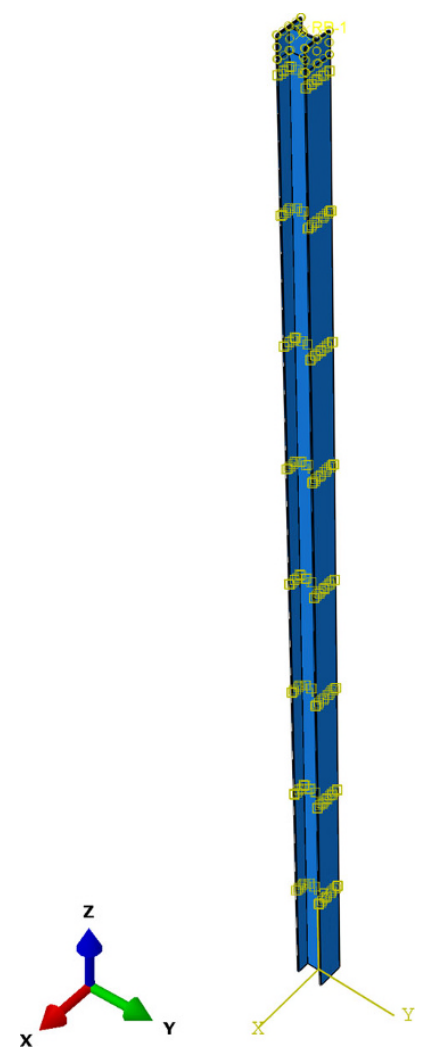

Fig. 2 Master surface in Abaqus/Cae defining the contact behavior between steel and sand and the rigid body elements at the top of the pile embedded in the pile cap 

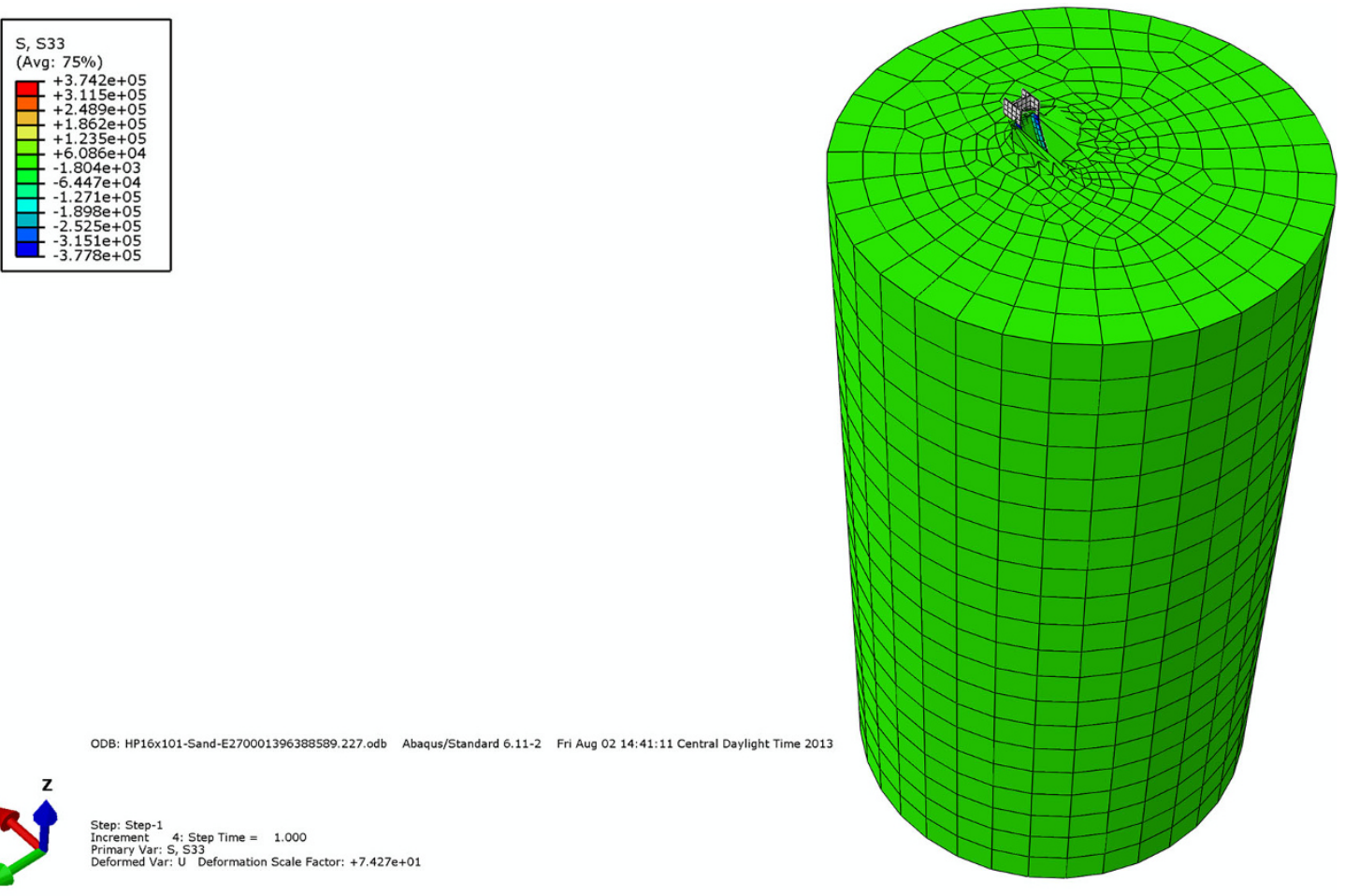

Fig. 3 A schematic diagram of the cross-sectional elevation of the Instrumented Bridge (Khodair and Hassiotis 2013)

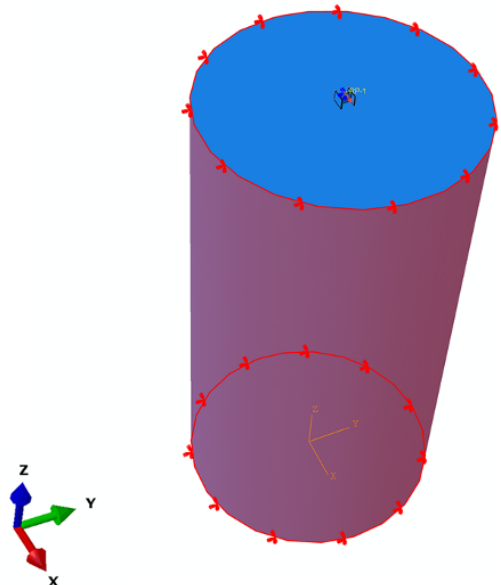

Fig. 4 Boundary conditions at the top of the pile and along the exterior surface of sand

$p-y$ curves (Reese et al. 2004). David and Forth (2011) investigated the use of finite element models at which the structure was assumed to behave linearly and soil is nonlinear. Sanjaya Kumar et al. (2007) investigated the performance of laterally loaded piles in high marine clay soil using ABAQUS and $p-y$ method. Also, Suleiman et al. (2010) conducted an experiment to measure the pile-soil interaction in laterally loaded piles having small diameters in loose sand soil. Chioui and Chenu (2007) presented an equivalent model for a linear pile-soil interaction of laterally loaded piles using a set of equivalent soil springs.
The soil commonly behaves like an elastic-plastic material. There are a large number of available soil constitutive models that can be used to represent the soil including Winkler Model, Mohr-Coulomb Model, (Modified) Cam-Clay model, Duncan-Chang Model, and Elastic Continuum Model. The Winkler Model is considered a simplified model, in which the soil can be modeled using linear or nonlinear springs. The Mohr-Coulomb Model is elastic-perfectly plastic and takes into account the effect of stresses on the strength of soil. The failure criteria are defined by the friction angles and cohesion of soil. The (Modified) Cam-Clay Model is an elastic-plastic strain hardening model at which nonlinearity is modeled using hardening plasticity. The Duncan-Chang Model is also called hyperbolic model and it is stress-dependent model used to describe nonlinearity of cohesive and cohesionless soil. The Elastic Continuum Model represents infinite soil medium.

Due to the change in temperature, the bridge experiences expansions and contractions, which in turn are experienced by the supporting piles. The effect of this daily and seasonal temperature change is dependent on the magnitude of temperature change and the length of the bridge. This thermal loading shall be considered in the design of piles.

This research examines the pile-soil interaction for various types of sand soil including loose, medium, and dense sand. The objectives of this research are to: (1) use a 
Table 1 Number and locations of springs used to model the soil

\begin{tabular}{|c|c|c|c|c|c|c|c|}
\hline $\begin{array}{l}\text { Number of } \\
\text { nonlinear soil } \\
\text { springs }(n)\end{array}$ & 3 & 5 & 6 & 8 & 10 & 12 & 14 \\
\hline \multirow{13}{*}{$\begin{array}{l}\text { At distance } \\
\text { from top of } \\
\text { the pile }(\mathrm{m})\end{array}$} & \multirow[t]{3}{*}{0} & 0 & 0 & 0 & 0 & 0 & 0 \\
\hline & & 0.61 & 0.61 & 0.61 & 0.61 & 0.61 & 1.22 \\
\hline & & & & & & 1.22 & 1.83 \\
\hline & \multirow[t]{4}{*}{1.22} & 1.22 & 1.22 & 1.22 & 1.22 & 1.83 & 2.44 \\
\hline & & & & & & 2.44 & 3.05 \\
\hline & & & 3.51 & 2.36 & 2.36 & 3.05 & 3.66 \\
\hline & & 3.51 & & 3.51 & 3.51 & 3.66 & 4.27 \\
\hline & \multirow[t]{6}{*}{5.79} & & 5.79 & 4.65 & 4.65 & 4.27 & 4.88 \\
\hline & & & & & & 4.88 & 5.49 \\
\hline & & 5.71 & & 5.79 & 5.79 & 5.49 & 5.79 \\
\hline & & & 10.36 & 10.36 & 8.08 & 5.79 & 8.08 \\
\hline & & & & & 10.36 & 10.36 & 10.36 \\
\hline & & & & & 12.65 & & 12.65 \\
\hline
\end{tabular}

number of software to evaluate pile-soil interaction, such as the finite difference software LPILE (2012) and the finite element software Abaqus/Cae and SAP2000, (2) compare the bending moments and lateral displacements induced along the depth of the pile using the finite difference method and the finite element models, and (3) conduct a parametric study to determine the effect of relevant design parameters which include the soil modulus of elasticity, varying the sand soil type including loose, medium, dense sand, and varying the number of soil springs on the pile induced bending moment and lateral displacements along its depth. In order to achieve the objectives of this research, the authors (1) employed a 2D finite difference (FD) method model using LPILE, (2) developed 3D finite element (FE) models of the pile-soil system using Abaqus/Cae and SAP2000, and (3) analyzed the effect of crucial design parameters, which were listed before, on piles bending moment and lateral displacement and then drew our conclusions.

\section{Bridge description}

The bridge studied is a steel girder bridge. It consists of one span with span length of about $45.5 \mathrm{~m}$ and width of $32.18 \mathrm{~m}$. The reinforced concrete deck is $\sim 25.4 \mathrm{~cm}$ thick and the spacing between stringers is $3.35 \mathrm{~m}$. The abutment is supported using HP $16 \times 101$ A572 steel piles.

Finite difference method model

A 2D finite difference (FD) model of the pile-soil interaction was developed using LPILE (2012). The model is based on stress equilibrium in 2D solved using the finite difference method. The pile was modeled according to the exact dimensions of an HP $16 \times 101$. The soil profile consists of four layers: three layers of sand and one layer of weak rock (Fig. 1). The angles of friction of the three layers of sand are $32^{\circ}, 30^{\circ}$, and $26^{\circ}$ from top to bottom.
Fig. 5 Sample of generated $p-y$ curves at predefined locations along the depth of the pile using the FD solution by LPILE

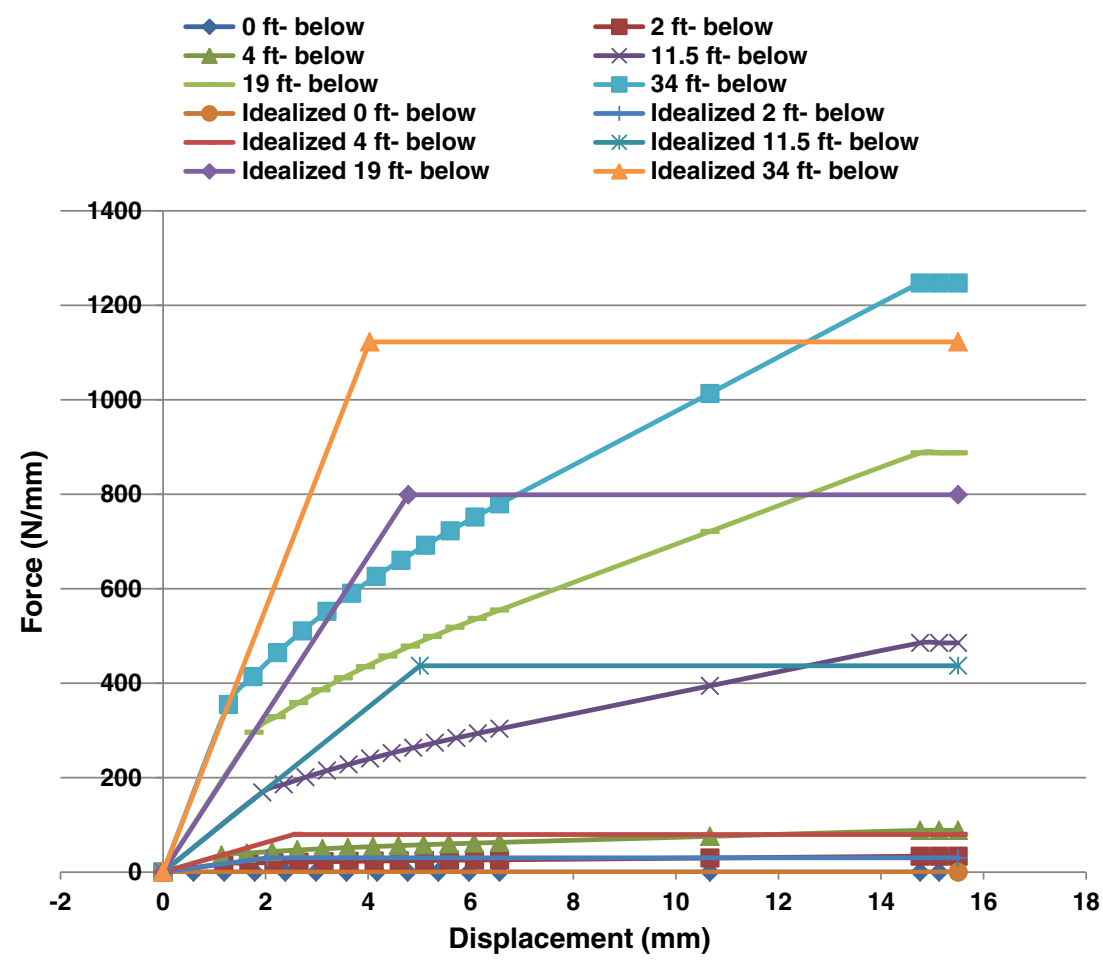




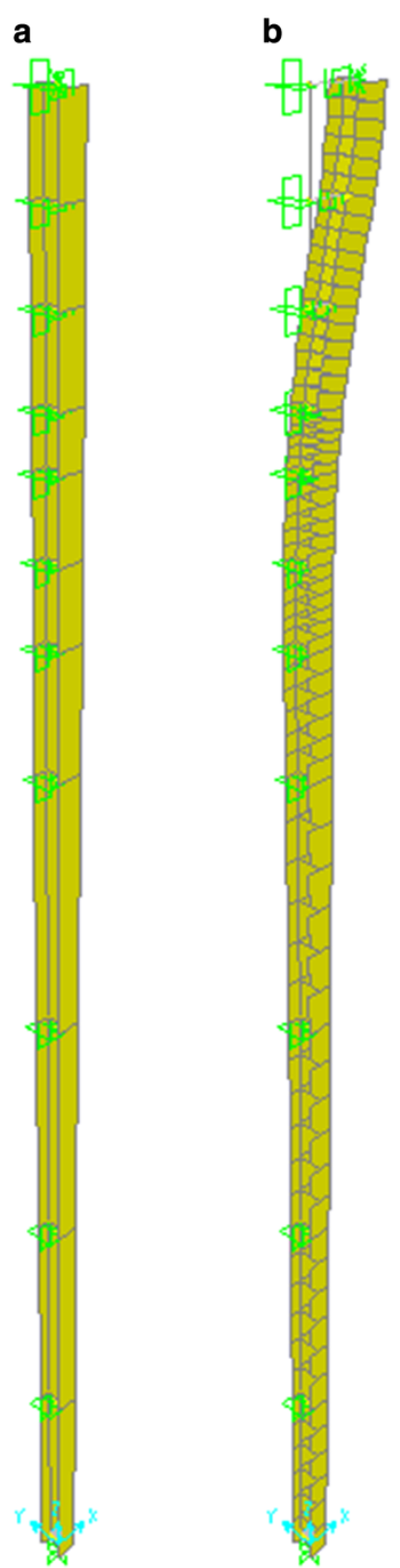

Fig. 6 Pile model overview using SAP2000. a Undeformed shape of pile and $\mathbf{b}$ deformed shape of pile due to a lateral displacement of $2 \mathrm{~cm}$

The pile is oriented such that bending is about the weak axis. Figure 1 shows the properties used to define the sand layers and weak rock layer in LPILE. Also, in LPILE, the sand soil type was varied as loose, medium, and dense having $k$ of $6,790,24,430$, and $61,000 \mathrm{kPa} / \mathrm{m}$, respectively.

\section{Finite element models}

Two 3D finite element models of the pile-soil interaction were developed using the finite element software Abaqus/ Cae and SAP2000 to study the nonlinear behavior of the soil.
In the Abaqus/Cae model, an elastic model was adopted for modeling the steel piles with a modulus of elasticity of $200,000 \mathrm{MPa}$. The studied soils are loose, medium, and dense sand with $\gamma$ of $2,002 \mathrm{~kg} / \mathrm{m}^{3}$ and $k$ varying as 6,790 , 24,430 , and $61,000 \mathrm{kPa} / \mathrm{m}$, respectively. A strain hardening model using Mohr-Coulomb failure criterion was adopted for the soil. For all sands, a Poisson's ratio of 0.25 and an angle of internal friction of $30^{\circ}$ were used in the definition of the Mohr-Coulomb failure criterion. To study the loose sand, the modulus of elasticity of the sand was varied between 10,000 and $30,000 \mathrm{kPa}$ to determine the proper modulus of elasticity that can be used to represent the loose sand. More effort was required to study the medium sand. The modulus of elasticity of the sand was varied between 10,000 and $69,000 \mathrm{kPa}$ to determine the proper modulus of elasticity that can be used to represent the medium sand. It was necessary to further refine the initial values of modulus of elasticity that were considered to arrive at the proper modulus of elasticity that can be used to realistically represent the medium sand. To study the dense sand, larger values of modulus of elasticity of the sand were considered and varied between 40,000 and $69,000 \mathrm{kPa}$ to determine the proper modulus of elasticity that can be used to represent the dense sand. The interaction between the sand and the pile was modeled by defining tangential and normal contact behavior in the FE model. A master and slave surfaces were defined in the FE model as shown in Fig. 2. The master surface was represented by the exterior surface of the pile, and the slave surface by interior surface of the sand which was extruded according to the exact dimensions of the pile. The tangential contact between the two surfaces was defined using a friction coefficient of 0.58 . A relatively fine mesh was adopted for the pile and a coarser mesh was adopted for the sand soil as shown in Fig. 3. In this model, the pile and sand were modeled using eightnodded solid continuum elements (C3D8R) to account for the continuum nature of the soil in Abaqus/Cae. The bottom of the pile was fixed into the FE model to simulate the embedment of the pile into rock below a depth of $14.94 \mathrm{~m}$ and the exterior surface of the soil cylinder was fixed to model the confinement of the soil at its limits as shown in Fig. 4. The degrees of freedom of the elements at the top of the pile were restrained to a reference point defined at the centroid of the pile's cross section in what defines a rigid body motion to model the guided fixation occurring due to the embedment of the top of the pile into the pile cap for a distance of about $0.3 \mathrm{~m}$.

In the SAP2000 model, an elastic three-dimensional (3D) frame element was adopted for modeling the steel piles. The steel pile, made of A572 steel with a modulus of elasticity of $200,000 \mathrm{MPa}$ and yield strength of $345 \mathrm{MPa}$, was used. The soil was modeled using nonlinear springs. Various number of soil springs were tried for loose, medium, and dense sand 


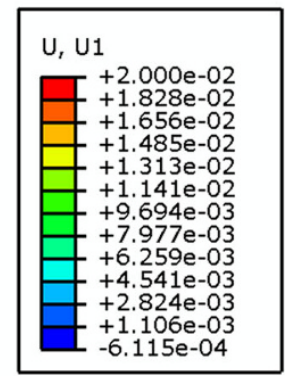

ODB: HP16x101-Sand-E270001396389110.082.odb Abaqus/Standard 6.11-2 Fri Aug 02 14:41:11 Central Daylight Time 2013

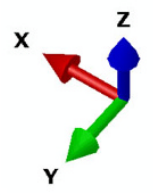

Step: Step-1

Increment $4:$ Step Time $=1.000$

Primary Var: U, U1

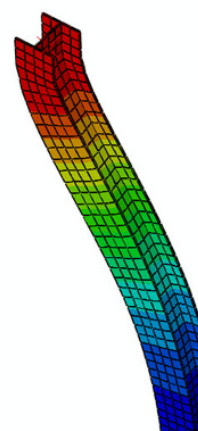

Fig. 7 A contour plot of pile lateral displacement, $U_{1}$ due to an imposed lateral displacement of $2 \mathrm{~cm}$ at the top of the pile

to determine the suitable number and distribution of springs that can be used with each type of sand. Table 1 shows the number and distribution of nonlinear soil springs that were considered and studied for each type of sand. Plastic (Wen) link element available in SAP2000 was used to model the hysteresis of soil. The springs were assigned in the longitudinal direction of the bridge. The nonlinear properties of the link elements were obtained using the generated $p-y$ curves from the FD solution by LPILE (Fig. 5). The number of soil springs were varied to investigate the effect of changing the number of springs on the performance of the pile and to determine the proper number of springs that should be used. The seven alternatives (Table 1) include using $3,5,6,8,10,12$, and 14 springs along the depth of the pile: (1) in the 3 springs model, springs were assigned at 0 , 1.22 , and $5.79 \mathrm{~m}$ below the top of the pile, (2) in the 5 springs model, springs were assigned at $0,0.61,1.22,3.51$, and $5.71 \mathrm{~m}$ below the top of the pile, (3) in the 6 springs model, springs were assigned at $0,0.61,1.22,3.51,5.79$, and $10.36 \mathrm{~m}$ below the top of the pile, (4) in the 8 springs model, springs were assigned at $0,0.61,1.22,2.36,3.51$, $4.65,5.79$, and $10.36 \mathrm{~m}$ below the top of the pile, (5) in the 10 springs model, springs were assigned at $0,0.61,1.22$, $2.36,3.51,4.65,5.79,8.08,10.36$, and $12.65 \mathrm{~m}$ below the top of the pile, (6) in the 12 springs model, springs were assigned at $0,0.61,1.22,1.83,2.44,3.05,3.66,4.27,4.88$, $5.49,5.79$, and $10.36 \mathrm{~m}$ below the top of the pile, and (7) in the 14 springs model, springs were assigned at $0,0.61,1.22$, $1.83,2.44,3.05,3.66,4.27,4.88,5.49,5.79,8.08,10.36$, and $12.65 \mathrm{~m}$ below the top of the pile. The $p-y$ curves were developed in LPILE at the defined depth locations and hence the soil stiffness at various depth locations was calculated and hysteretic behavior was obtained. Fixity was assigned at the bottom of the pile to simulate the embedment of the pile into rock below a depth of $14.94 \mathrm{~m}$ as shown in Fig. 6. The degrees of freedom of the elements at the top of the pile were restrained in a way to define a rigid body motion to model the guided fixation due to the embedment of the top of the pile into the pile cap for a distance of $30 \mathrm{~cm}$.

\section{Loading}

In the first part of the study, a displacement of $2 \mathrm{~cm}$, which corresponds to a temperature change of $44{ }^{\circ} \mathrm{C}$ was applied to the reference point of the rigid body defined at the top of the pile to model the lateral displacement caused by 
Fig. 8 Bending moment, M22 in pile due to a lateral displacement of $0.02 \mathrm{~m}$

thermal expansions and contractions at the top of the pile, while imposing a zero slope (guided-fixation), without applying any axial load. In the second part of the study, the effect of the axial load $(300 \mathrm{kN})$, which corresponds to the dead and live loads resulting from the bridge superstructure was applied as a vertical load at the reference point defining the rigid body motion at the top of the pile to study the effect of including the axial load in addition to the lateral displacement on the induced bending moments and lateral displacements along the depth of the pile. Figures 3, 6,7 , and 8 show the lateral bending stress (S33), the lateral displacement $\left(\mathrm{U}_{1}\right)$, and the bending moment (M22) along the depth of the pile.

\section{Comparison between the FE models and LPILE}

The results obtained from the FE models (Abaqus/Cae and SAP2000) were compared to those produced by the FD model (LPILE 2012). The bending moment and lateral displacement induced along the depth of the pile due to a lateral displacement of $2 \mathrm{~cm}$ applied at the top of the pile were compared using the three models for verification purposes. Figures 9 through 22 show a comparison between the results of $\mathrm{FE}$ models by Abaques/Cae and
SAP2000 and results of LPILE solutions. Abaqus/Cae accounts for the continuum nature of the soil, while LPILE analysis is based on discrete definition of the soil, where the stiffness of the soil at one point does not affect the other. Models in SAP2000 have nonlinear soil springs assigned at different depth locations along the pile length.

\section{Parametric study}

A parametric study was conducted to analyze the effect of crucial design parameters such as the variation in sand type, variation in the magnitudes of modulus of elasticity, and the number of soil springs on the bending moment and lateral displacements induced along the depth of the pile.

\section{Effect of variation in modulus of elasticity}

As mentioned before, loose, medium, and dense sand were studied. Various values of modulus of elasticity were used to study the effect of the stiffness of the sand under a lateral deformation of $2 \mathrm{~cm}$. For the loose sand, the modulus of elasticity of the sand was varied between 10,000 and $30,000 \mathrm{kPa}$. For the medium sand, the modulus of elasticity of the sand was varied between 10,000 and $69,000 \mathrm{kPa}$, and further refinement of the initial values of modulus of elasticity was needed to arrive at the proper modulus of elasticity that can be used to realistically represent the medium sand. For the dense sand, larger values of modulus of elasticity of the sands were considered and varied between 40,000 and 69,000 kPa. For example, Figs. 9 and 10 show that as the magnitude of the modulus of elasticity increases, the curves for the bending moments and lateral displacements calculated by Abaqus/Cae and those produced by LPILE approach each other. Figures 9 and 10 show a comparison between the bending moments and lateral displacements calculated by Abaqus/Cae and LPILE for loose sand. Figures 11 and 12 show a comparison between the bending moments calculated by Abaqus/Cae and LPILE for medium sand, whereas Figs. 13 and 14 show a comparison between the calculated lateral displacements for medium sand. Figures 15 and 16 show a comparison between the bending moments and lateral displacements calculated by Abaqus/Cae and LPILE for dense sand. In the loose sand, modulus of elasticity of $10,000,27,000$, and 30,000 kPa was used in Abaqus/Cae to calculate the bending moments and lateral displacements in the pile to compare these results to those obtained using LPILE. From Figs. 9 and 10, it can be observed that a modulus of elasticity of $27,000 \mathrm{kPa}$ is a good representation of the loose sand since using this value resulted in good agreement. In the medium sand, initially, modulus of elasticity of $10,000,27,000,35,000$, and $69,000 \mathrm{kPa}$ were 
Fig. 9 Comparison between the bending moment versus pile depth obtained from the FE model Abaqus/Cae and FD solutions by LPILE for soft sand due to a lateral displacement of $2 \mathrm{~cm}$

Fig. 10 Comparison between the lateral displacement versus pile depth obtained from the FE model Abaqus/Cae and FD solutions by LPILE for soft sand due to a lateral displacement of $2 \mathrm{~cm}$

\section{Bending Moment (kN.m)}

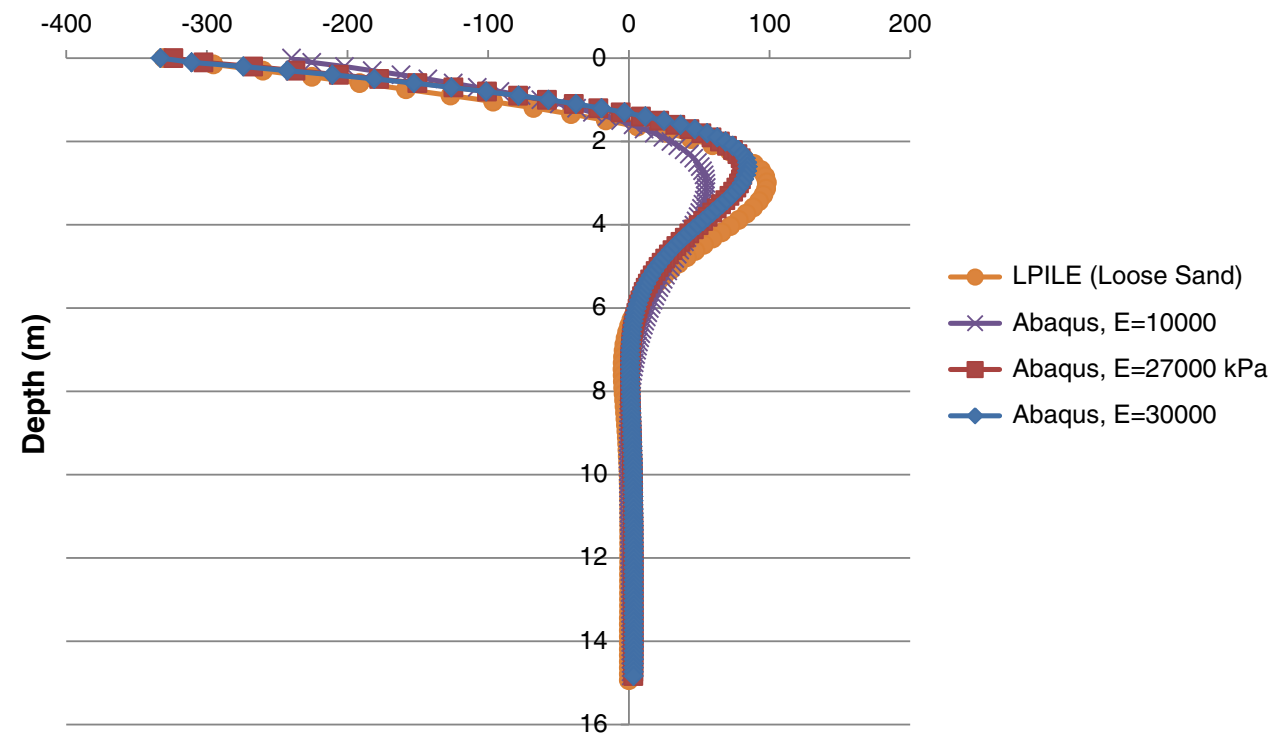

Lateral Displacement (m)

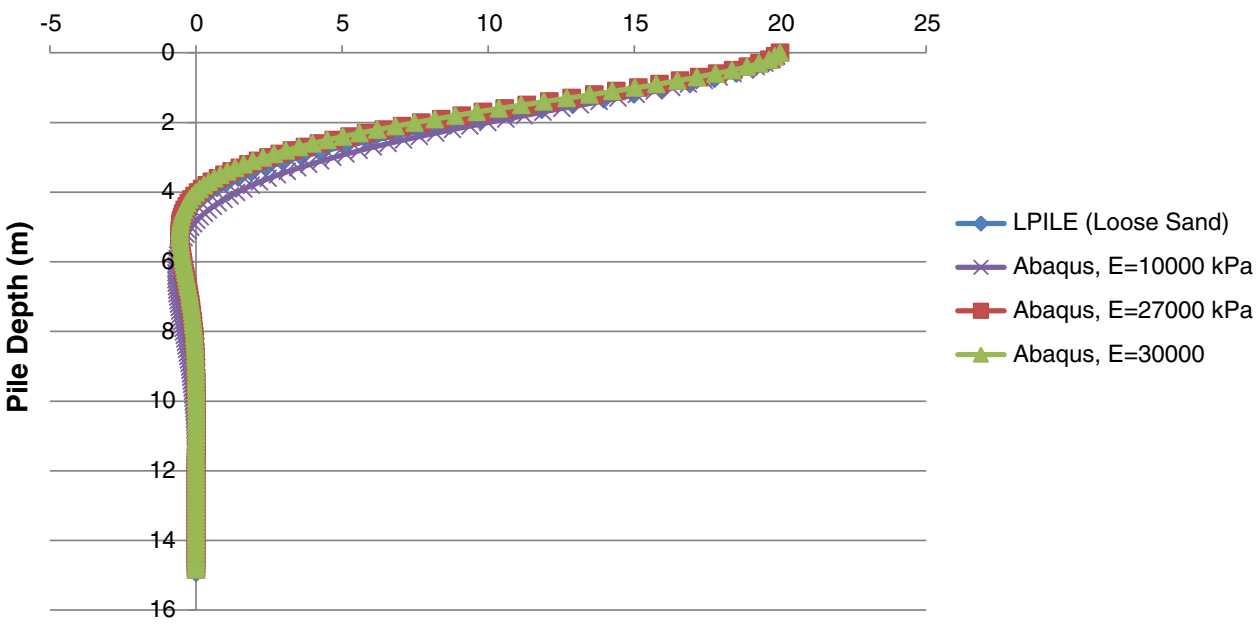

used in Abaqus/Cae to calculate the bending moments and lateral displacements in the pile. Using this set of modulus of elasticity values did not result in good agreement between results of Abaqus/Cae and LPILE; therefore, it was necessary to further refine and hence a modulus of elasticity of $30,000 \mathrm{kPa}$ was used. It can be observed that a modulus of elasticity of $30,000-35,000 \mathrm{kPa}$ is a good representation of the medium sand since using these values resulted in good agreement as shown in Figs. 11, 12, 13, and 14. In the dense sand, modulus of elasticity of 40,000, 50,000 , and $69,000 \mathrm{kPa}$ were used in Abaqus/Cae to calculate the bending moments and lateral displacements in the pile and compare these results to those of LPILE as shown in Figs. 15 and 16. It can be observed that a modulus of elasticity of $50,000-69,000 \mathrm{kPa}$ is a good representation of the dense sand since using this value resulted in good agreement.

It should be noted that soil definition in Abaqus/Cae and LPILE models was not the same, as explained earlier. In conclusion, loose, medium, and dense sand can be modeled using modulus of elasticity of $27,000 \mathrm{kPa}, 30,000-35,000$ $\mathrm{kPa}$, and 50,000-69,000 kPa, respectively.

Effect of variation in number of soil springs

In SAP2000, various types of sands were also studied including loose, medium, and dense sand. The soil was modeled using nonlinear springs that were assigned at different depths from the top of the pile. This approach is similar to that in LPILE since it is based on discrete 
Fig. 11 Comparison between the bending moment versus pile depth obtained from the FE model Abaqus/Cae and FD solutions by LPILE for different sand moduli of elasticity due to a lateral displacement of $2 \mathrm{~cm}$

\section{Bending Moment (kN.m)}

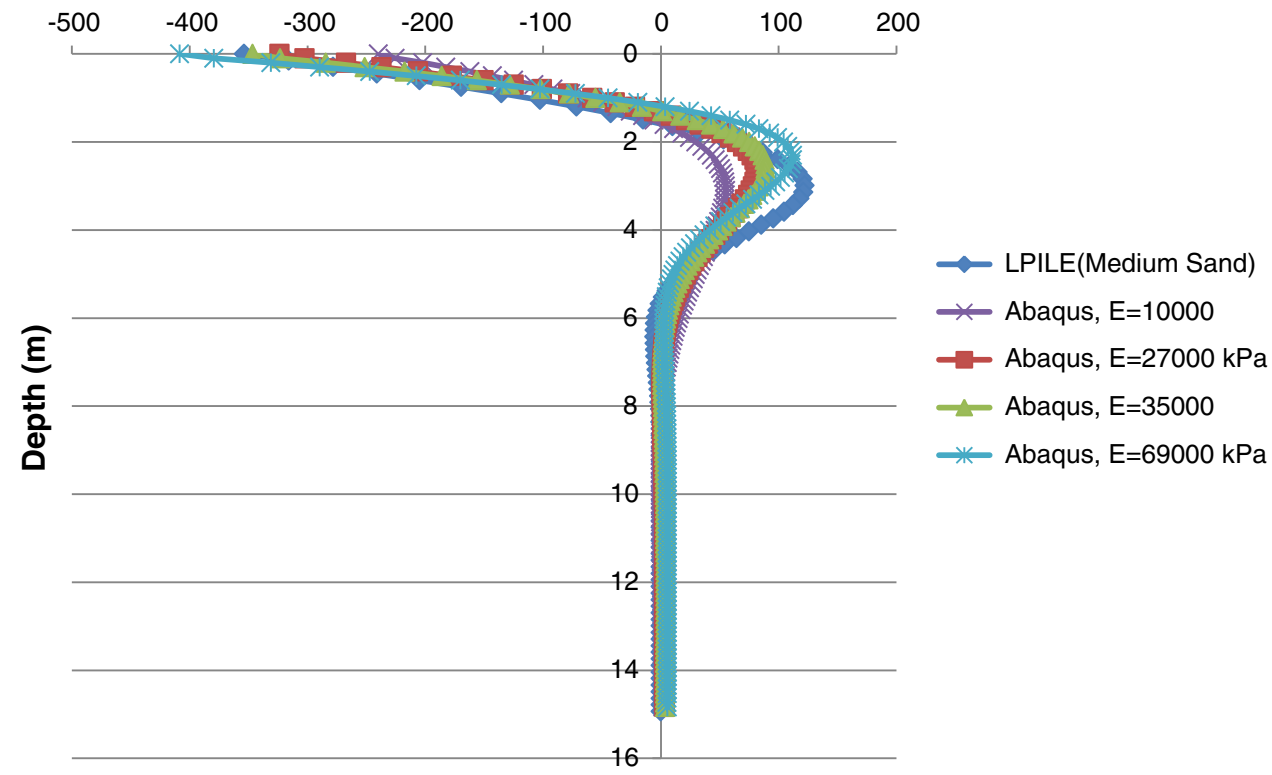

Bending Moment (kN.m)

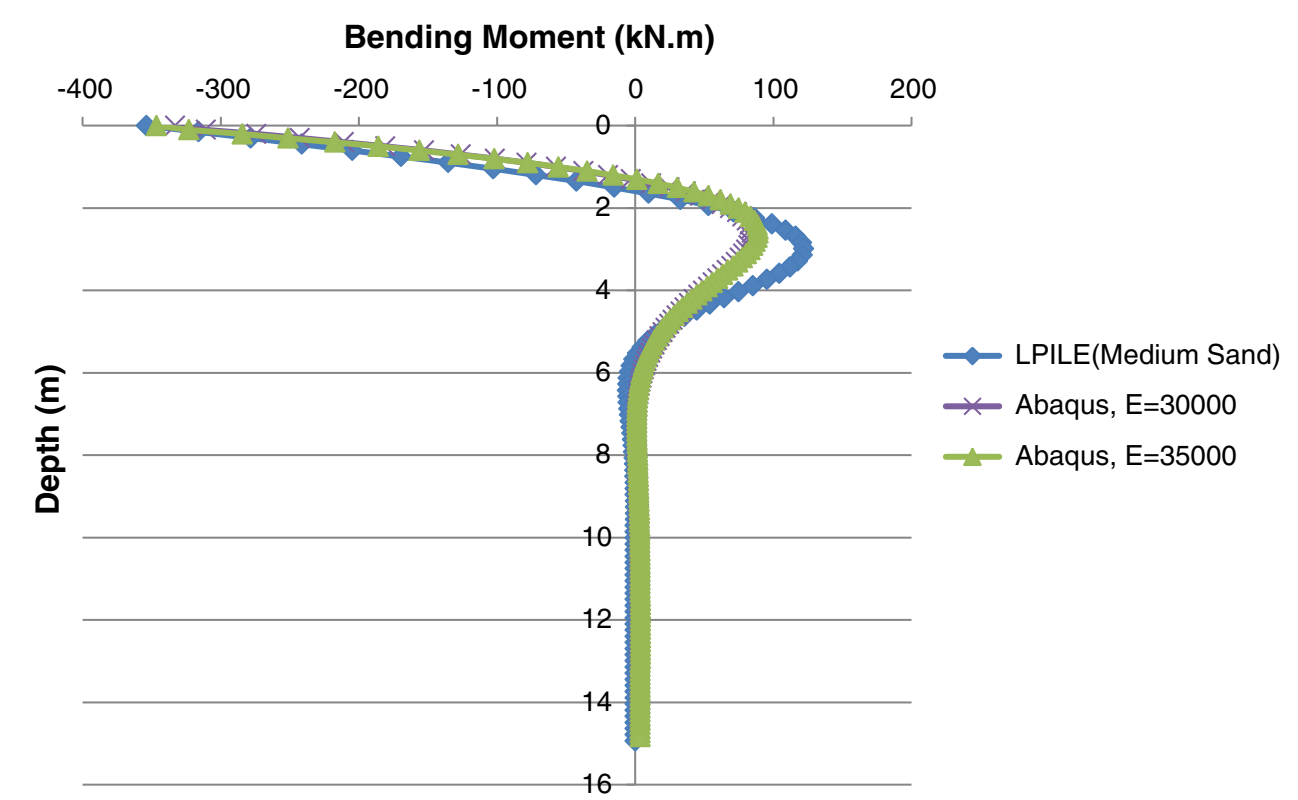

Fig. 12 Comparison between the bending moment versus pile depth obtained from the FE model Abaqus/Cae and FD solutions by LPILE for medium sand due to a lateral displacement of $2 \mathrm{~cm}$ definition of the soil thus the soil is not modeled as a continuum media. The number of soil springs were varied to investigate the effect of changing the number of springs on the performance of the pile and to determine the proper number of springs that shall be used to model pile-soil interaction, adequately in loose, medium, and dense sand. Seven alternatives were used including using 3 springs, 5 springs, 6 springs, 8 springs, 10 springs, 12 springs, and 14 springs. Table 1 shows number and locations of nonlinear springs assigned to the piles for all of the seven alternatives, which were tested. The soil hysteretic properties such as yield strength and stiffness were calculated based on the $p-y$ curves generated in LPILE at the defined depth locations (Fig. 5). For example, Figs. 17 and 18 show that as the number of springs increases, the magnitude of bending moment and lateral displacements experienced in the pile from SAP2000 approach that obtained from LPILE. Figures 17 and 18 show a comparison between the bending moments and lateral displacements calculated by SAP2000 and LPILE for loose sand. Figures 19 and 20 show a comparison between the bending moments and lateral displacements calculated by SAP2000 and LPILE for medium sand. Figures 21 and 22 show a comparison between the bending moments and lateral displacements 
Fig. 13 Comparison between the lateral displacement versus pile depth obtained from the FE model Abaqus/Cae and FD solutions by LPILE for LPILE for different sand moduli of elasticity due to a lateral displacement of $2 \mathrm{~cm}$

\section{Lateral Displacement (m)}

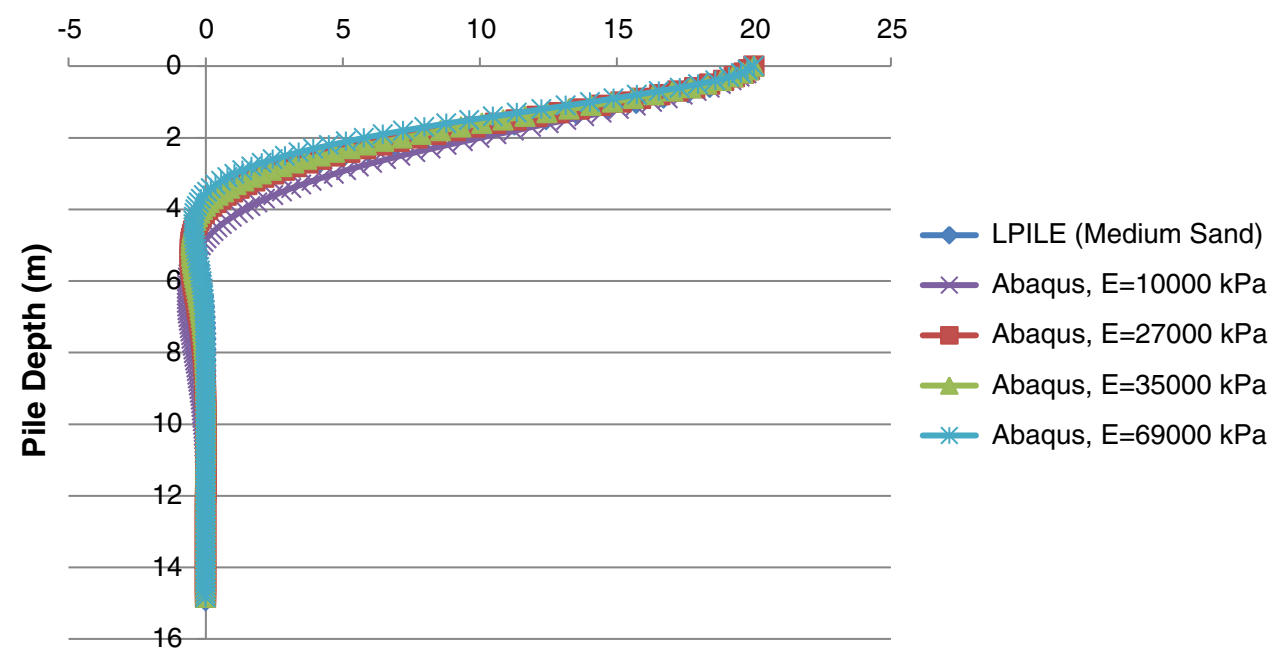

Lateral Displacement (m)

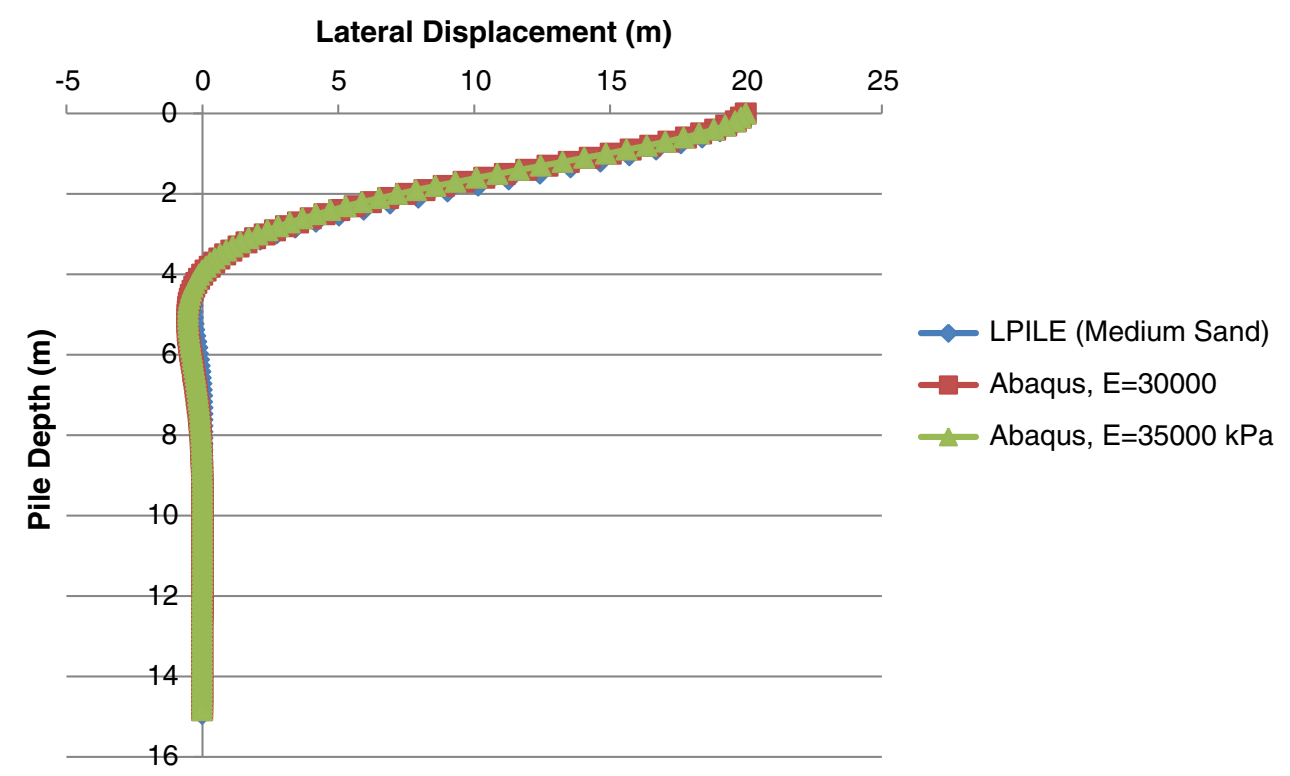

Fig. 14 Comparison between the lateral displacement versus pile depth obtained from the FE model Abaqus/Cae and FD solutions by LPILE for medium sand due to a lateral displacement of $2 \mathrm{~cm}$ calculated by SAP2000 and LPILE for dense sand. The magnitude of moment decreases moving downward from the top of the pile. A similar trend can be observed for the lateral displacement of the pile (e.g., Fig. 18). As the sand becomes stiffer, the induced moment in the pile is larger. Also, using a larger number of springs leads to a better agreement between the bending moment and lateral displacement results from SAP2000 and LPILE. It can be observed that using 12 springs led to a good match between results of SAP2000 and LPILE; however, the use of 14 springs led to accurate results as well. A better correlation can be obtained using a more refined model through increasing the number of nonlinear soil springs, however, the agreement associated with using 12 springs was considered reasonable and acceptable for all of loose, medium, and dense sand.
Effect of applying axial load

A comparison was conducted for only medium soil between LPILE, Abaqus/Cae, and SAP2000 to study the effect of applying an axial load of $300 \mathrm{kN}$ to the pile on the bending moments and lateral displacements that are induced along the depth of the pile due to the applied displacement of $2 \mathrm{~cm}$ at the top of the pile. It seems that the applied axial load did not significantly affect neither the induced bending moments nor lateral displacements in the pile (Figs. 23, 24, 25). In Abaqus/Cae, the recommended modulus of elasticity, which was determined before, of $30,000 \mathrm{kPa}$ was used. Applying the axial load did not show any significant effect on the induced bending moment and the results obtained from Abaqus/Cae closely matched those from LPILE (Fig. 23). In SAP2000, the recommended arrangement of 
Fig. 15 Comparison between the bending moment versus pile depth obtained from the FE model Abaqus/Cae and FD solutions by LPILE for dense sand due to a lateral displacement of $2 \mathrm{~cm}$
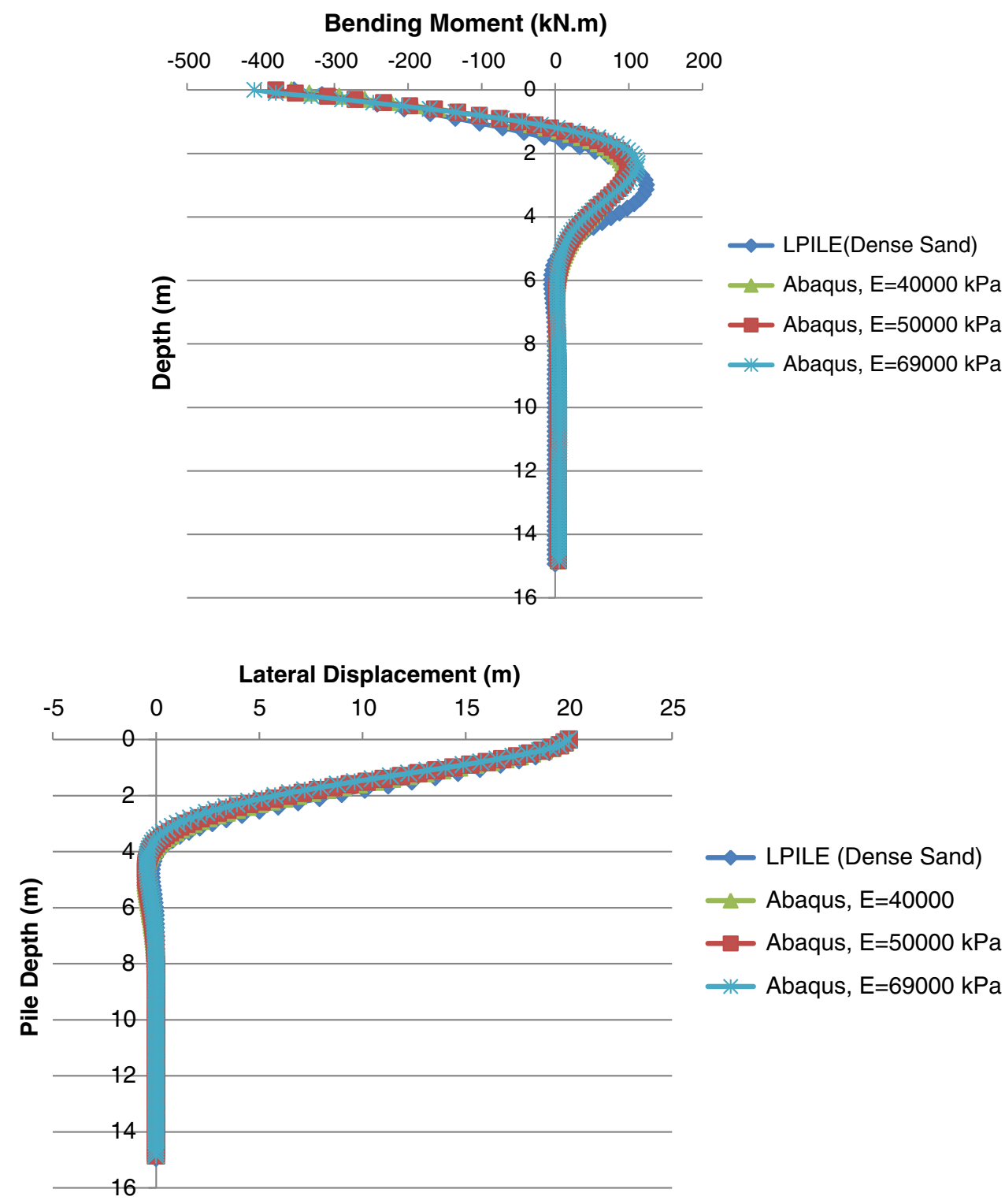

Fig. 16 Comparison between the lateral displacement versus pile depth obtained from the FE model Abaqus/Cae and FD solutions by LPILE for medium sand due to a lateral displacement of $2 \mathrm{~cm}$
12 springs, which was determined before, was used and it was found that applying the axial load did not show an obvious effect on the induced bending moments and lateral displacements and also these results closely matched those from LPILE (Figs. 24, 25).

\section{Summary and conclusions}

A comparative study to analyze pile-soil interaction in soft soil under lateral loading was conducted. A 2D finite difference method model was developed using LPILE (2012). In this model, the pile was modeled according to the exact dimensions of a HP $16 \times 101$. Various types of sands were studied including loose, medium, and dense sand. The pile is oriented such that bending is about the weak axis. Two
3D finite element models were developed using the finite element software Abaqus/Cae and SAP2000. In the 3D finite element model developed using Abaqus/Cae, both the pile and the soil were modeled using solid continuum elements (C3D8R) to account for the continuity of the soil. An elastic model was adopted for the pile. A Mohr-coulomb failure criterion was defined for the sands. The contact behavior between the piles and the soil was defined using tangential and normal algorithms in ABAQUS/Cae. A rigid body motion was defined at the top of the pile by tying the degrees of freedom of the elements embedded in the pile cap ( $30 \mathrm{~cm}$ from the top of the pile) to a reference point at the centroid of the pile's cross section. In the $3 \mathrm{D}$ finite element model developed using SAP2000, the pile was modeled using a continuum 3D frame element while the soil was modeled using a number of nonlinear soil 
Fig. 17 Comparison between the bending moment versus pile depth obtained from the FE model SAP2000 and FD solutions by LPILE for loose sand due to a lateral displacement of $2 \mathrm{~cm}$
Fig. 18 Comparison between the lateral displacement versus pile depth obtained from the FE model SAP2000 and FD solutions by LPILE for loose sand due to a lateral displacement of $2 \mathrm{~cm}$
Bending Moment (kN-m)

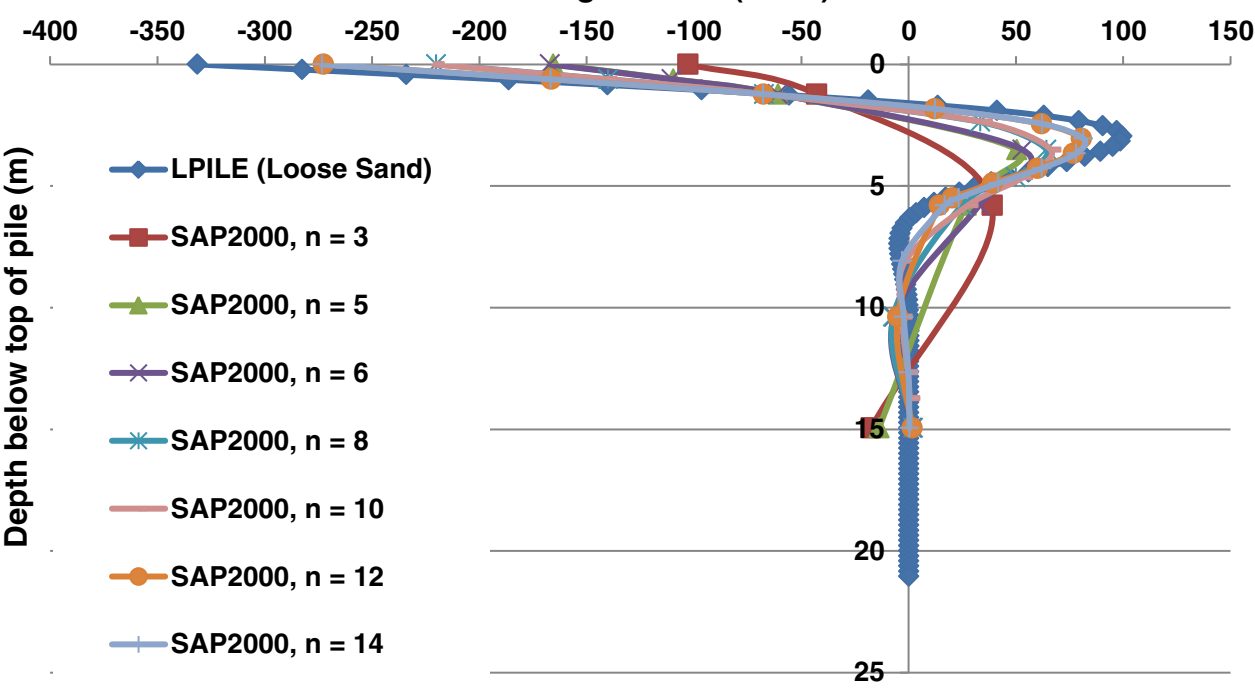

Lateral Displacement ( $\mathrm{mm}$ )

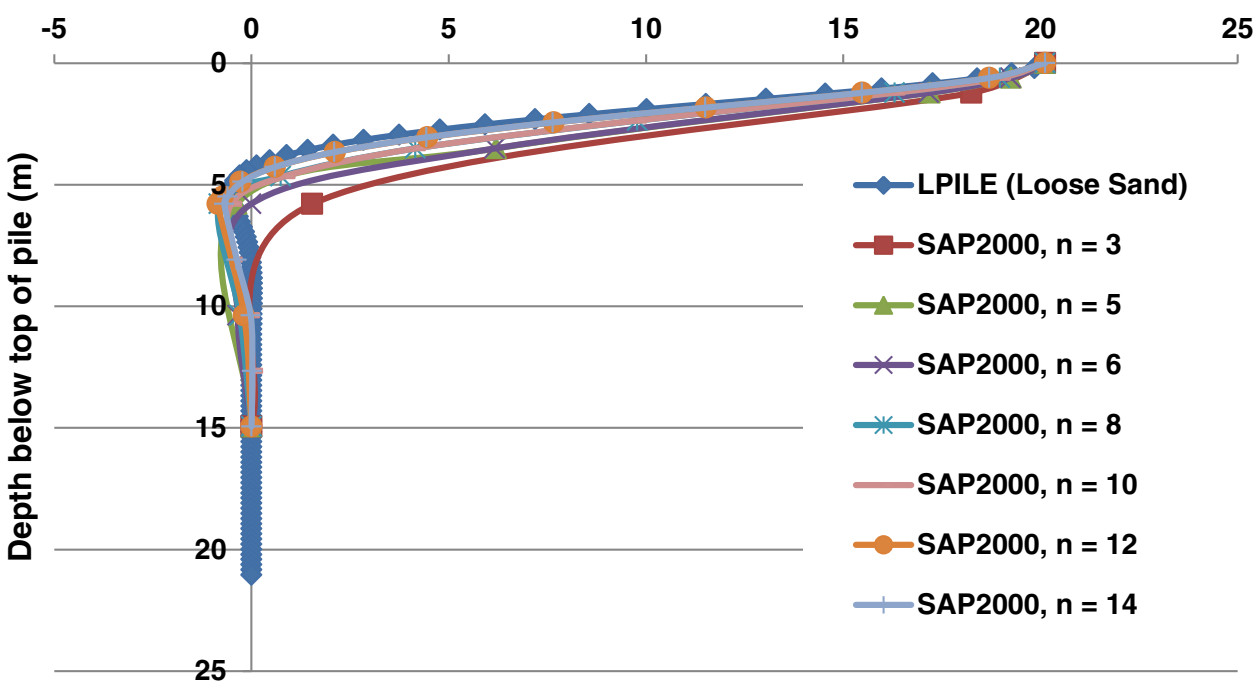

springs at predefined depth locations. The properties of the pile were the elastic properties of HP $16 \times 101$. The nonlinear soil properties were obtained using the $p-y$ curves generated in LPILE at the predefined depth locations and modeled using the Plastic (Wen) link element available in SAP2000. A rigid body motion was defined at the top of the pile by assigning the proper degrees of freedom to the elements embedded in the pile cap to maintain a zero slope in what simulates a guided fixation due to the embedment of the top of the pile into the pile cap for a distance of $30 \mathrm{~cm}$. The bottom of the steel pile was fixed to model its embedment into rock below a depth of $14.94 \mathrm{~m}$ from the top of the pile. Also, a displacement of $2 \mathrm{~cm}$ was applied at the top of the pile.
A parametric study was conducted to examine the effect of crucial design parameters such as the variation in the magnitudes of modulus of elasticity of the sands and the number of soil springs on the bending moment and lateral displacements due to an applied axial load and lateral displacement of $2 \mathrm{~cm}$ at the top of the pile. The magnitude of the modulus of elasticity was varied to determine the proper value of modulus of elasticity that represents each type of sand in consideration as the sand was varied from loose to dense. For all sands, as the magnitude of the modulus of elasticity increases, the magnitudes of the bending moment and lateral displacements induced along the depth of the pile predicted by Abaqus/Cae and those obtained from LPILE approach each others in loose, 
Fig. 19 Comparison between the bending moment versus pile depth obtained from the FE model SAP2000 and FD solutions by LPILE for medium sand due to a lateral displacement of $2 \mathrm{~cm}$
Fig. 20 Comparison between the lateral displacement versus pile depth obtained from the FE model SAP2000 and FD solutions by LPILE for medium sand due to a lateral displacement of $2 \mathrm{~cm}$
Fig. 21 Comparison between the bending moment versus pile depth obtained from the FE model SAP2000 and FD solutions by LPILE for dense sand due to a lateral displacement of $2 \mathrm{~cm}$
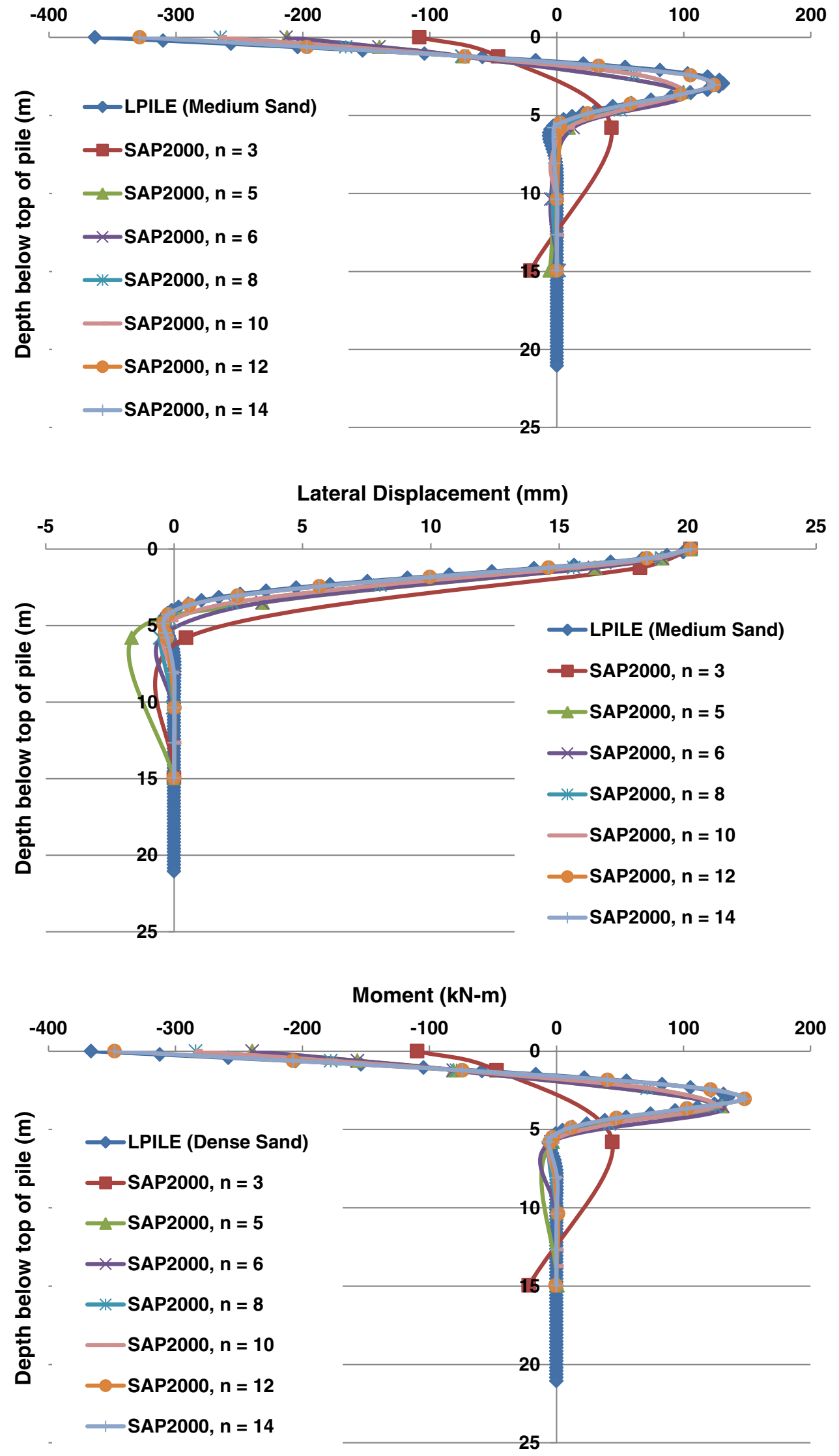
Fig. 22 Comparison between the lateral displacement versus model SAP2000 and FD solutions by LPILE for dense sand due to a lateral displacement of $2 \mathrm{~cm}$

Fig. 23 Effect of axial load on the bending moment versus pile depth obtained from the FE model Abaqus/Cae and FD solutions by LPILE pile depth obtained from the FE

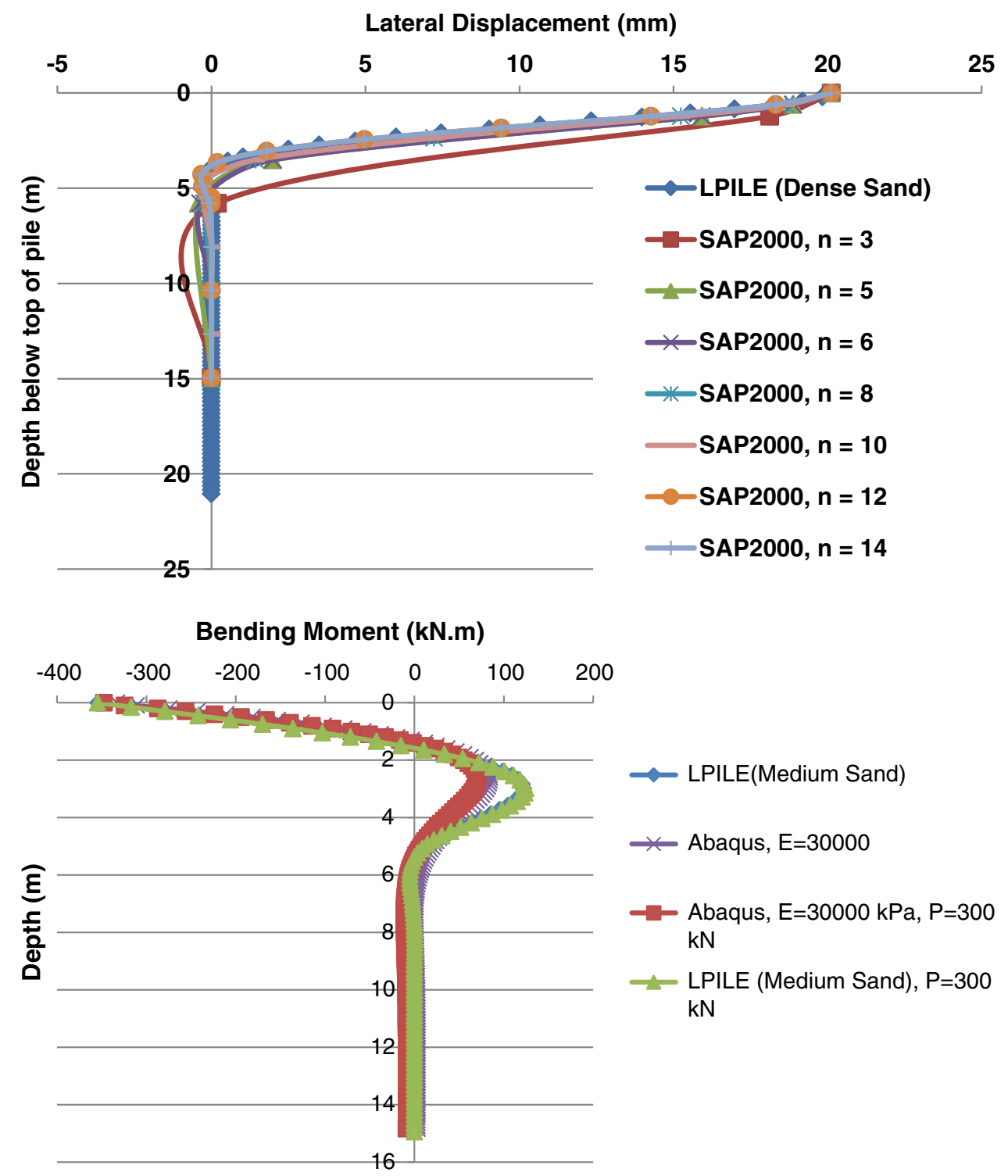

Fig. 24 Effect of axial load on the bending moment versus pile depth obtained from the FE model SAP2000 and FD solutions by LPILE

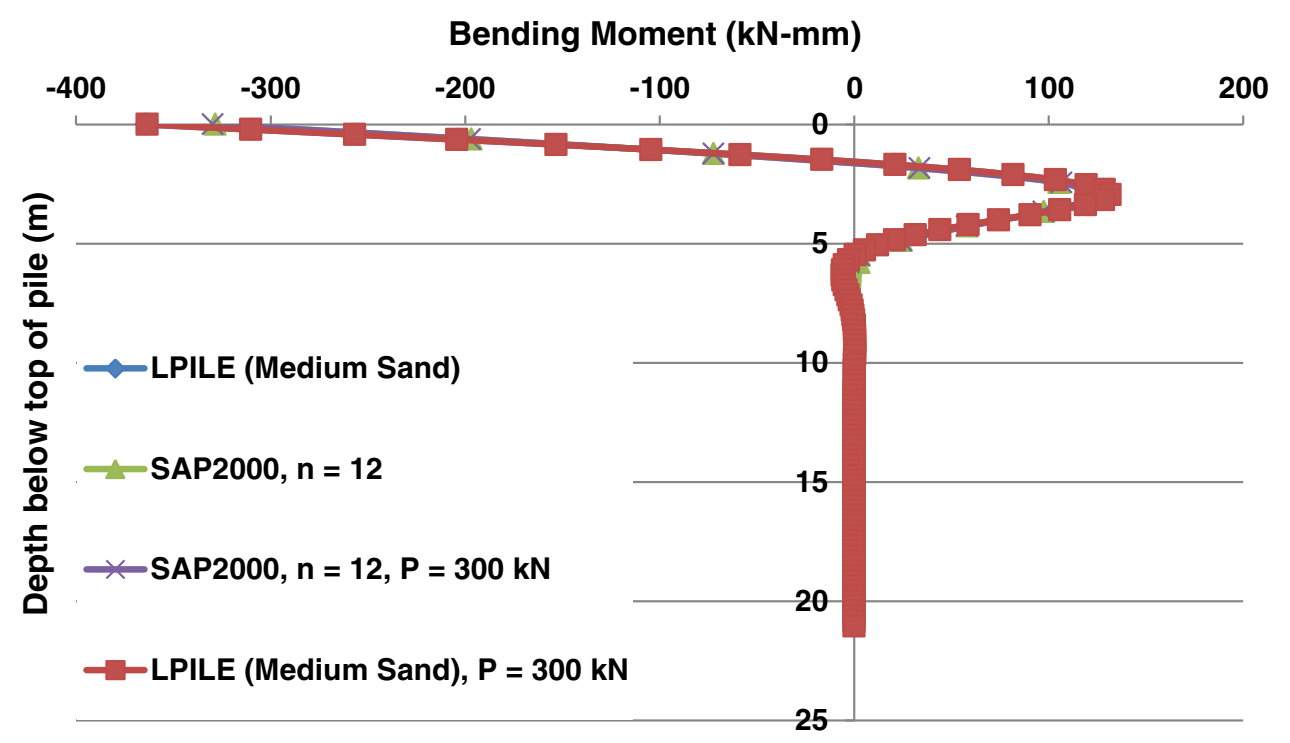


Fig. 25 Effect of axial load on the lateral displacement versus pile depth obtained from the FE model SAP2000 and FD solutions by LPILE

\section{Lateral Displacement (mm)}

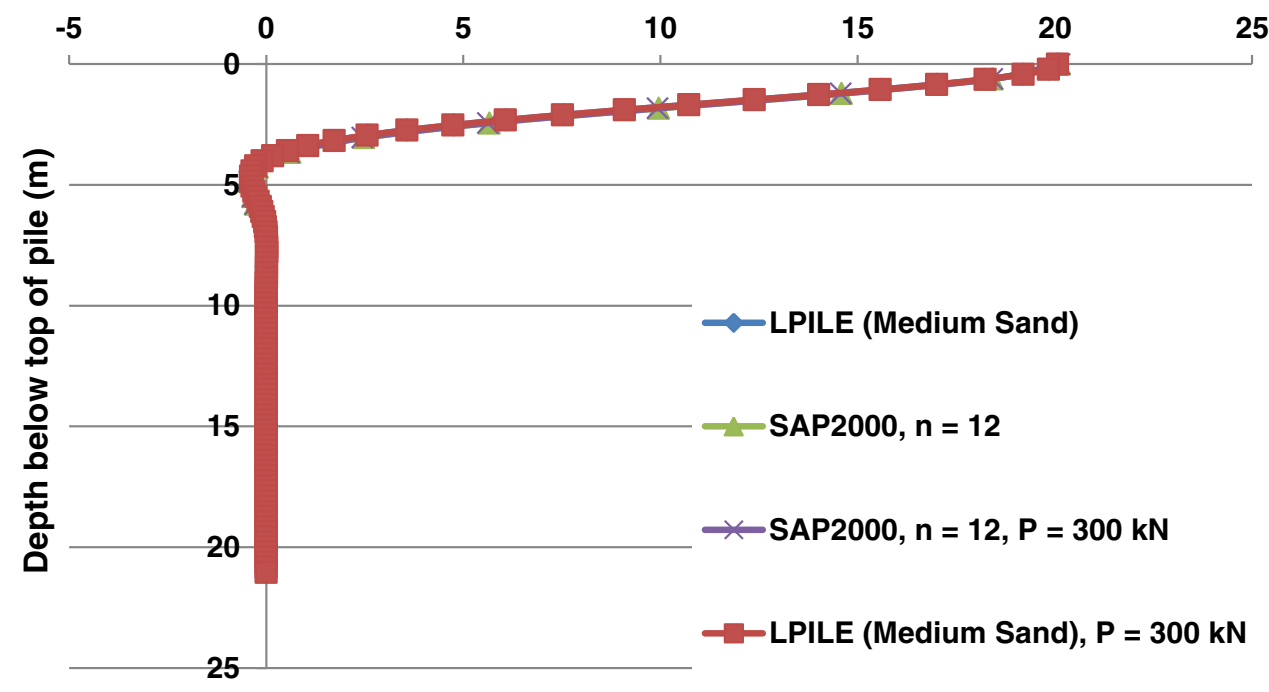

medium, and dense sand when modulus of elasticity of $27,000,30,000$, and $50,000 \mathrm{kPa}$ was used, respectively.

The effect of varying the number of soil springs on the induced bending moment and lateral displacement along the depth of the pile was examined using SAP2000. The results from SAP2000 were compared to those from FD solution by LPILE due to the effect of an induced displacement of $2 \mathrm{~cm}$ at the top of the pile for all types of sands. The number of nonlinear soil springs was varied between 3, 5, 6, 8, 10, 12 and 14 springs. Results of SAP2000 model with 12 springs showed good agreement with those from LPILE. However, as the number of nonlinear soil springs increases, a better agreement between bending moment and lateral displacement magnitudes from using SAP2000 and LPILE is obtained.

The results obtained from the FE models and FD solutions show that SAP2000 and Abaqus/Cae are capable of predicting the induced bending moments and lateral displacements along the depth of the pile in soft soil to similar level of accuracy. However, in Abaqus/Cae, the soil is modeled as a continuum media and, in SAP2000, the soil is defined using isolated springs. Overall, the results of Abaqus/Cae and SAP2000 are considered to be in a good agreement with those of LPILE.

Also, the effect of applying an axial load of $300 \mathrm{kN}$, to the pile on the produced bending moment and lateral displacement along the depth of the pile due to the applied displacement of $2 \mathrm{~cm}$ at the top of the pile, is negligible.

Open Access This article is distributed under the terms of the Creative Commons Attribution License which permits any use, distribution, and reproduction in any medium, provided the original author(s) and the source are credited.

\section{References}

Abdel-Mohti A, Pekcan G (2013a) Effect of skew on the seismic vulnerability of RC box girder highway bridges. Int J Stab Struct Dyn 13(6): 1-24

Abdel-Mohti A, Pekcan G (2013b) Assessment of seismic performance of skew reinforced concrete box girder bridges. Int $\mathrm{J}$ Adv Struct Eng 5(1):1-18

Avaei A, Ghotbi AR, Aryafar M (2008) Investigation of pile-soil interaction subjected to lateral loads in layered soils. Am J Eng Appl Sci 1(1):76-81

Banerjee PK, Davies TG (1978) The behavior of axially and laterally loaded single piles embedded in non-homogeneous soils. Geotechnique 21(3):309-326

Bransby MF, Springman S (1999) Selection of load transfer functions for passive lateral loading of pile groups. Comput Geotech 24:155-184

Brown DA, Shie C-F (1990a) Numerical experiments into group effects on the response of piles to lateral loading. Comput Geotech 10:211-230

Brown DA, Shie C-F (1990b) Three dimensional finite element model of laterally loaded piles. Comput Geotech 10:59-79

Brown DA, Shie C-F (1991) Some numerical experiments with a three dimensional finite element model of a laterally loaded pile. Comput Geotech 12:149-162

Chioui JS, Chenu CH (2007) Exact equivalent model for a laterallyloaded linear pile-soil system. Soils Found 47(6):1053-1061

Chore HS, Ingle RK, Sawant VA (2010) Parametric study of pile groups subjected to lateral load. Struct Eng Mech 36(2):243-246

David TK, Forth JP (2011) Modelling of soil structure interaction of integral abutment bridges. World Acad Sci Eng Technol 78:769-774

Davisson MT, Gill HL (1963) Laterally loaded piles in a layered soil system. J Soil Mech Found Div 89(SM3):63-94 May Paper 3509

Desai CS (1974) Numerical design and analysis of piles in sands. J Geotech Eng (ASCE) 100(6):613-635

Desai CS, Abel JF (1974) Introduction to finite element method. CBS Publishers, New Delhi

Desai CS, Appel GC (1976) 3-D analysis of laterally loaded structures. In: Proceedings of the 2nd international conference on numerical methods in geomechanics, Blacksburg 
Desai CS, Kuppusamy T, Alameddine AR (1981) Pile cap-pile group-soil interaction. J Struct Eng (ASCE) 107(5):817-834

Dewaikar DM, Verghese S, Sawant VA, Chore HS (2007) Non-linear 3-D FEA of laterally loaded pile group incorporating no-tension behaviour of soil. Indian Geotech J 37(3):174-189

Dicleli M, Albhaisi SM (2003) Maximum length of integral bridges supported on steel H-piles driven in sand. Eng Struct 25:1491-1504

Dutta SC, Roy R (2001) A critical review on idealization and modeling for interaction among soil-foundation-structure system. Comput Struct 80:1579-1594

Georgiadis M, Butterfield R (1982) Laterally loaded pile behaviour. J Geotech Eng (ASCE) 108(1):155-165

Hartog JPD (1952) Advanced strength of materials. Dover Publications Inc, NY

Khodair Y, Hassiotis S (2013) Numerical and experimental analyses of an integral bridge. Int J Adv Struct Eng 5(14):1-12

Kimura M, Adachi T, Kamei H, Zhang F (1995) 3-D finite element analyses of the ultimate behavior of laterally loaded cast-in-place concrete piles. In: Pande GN, Pietruszczak S (ed) Proceedings of the fifth international symposium on numerical models in geomechanics, NUMOG V, A. A. Balkema, pp 589-594, September 1995

Krishnamoorthy Rao NBS, Anil DS (2003) Non-linear analysis of group of piles. Indian Geotech J 33(4):375-395

Krishnamoorthy Rao NBS, Rao Nitin (2005) Analysis of group of piles subjected to lateral loads. Indian Geotech J 35(2):154-175

Kuhlemeyer RL (1979) Static and dynamic laterally loaded floating piles. J Geotech Eng (ASCE) 105(2):289-304

Lee SL, Karunaratne GP (1987) Laterally loaded piles in layered soil. Soils Found 27(4):1-10

Muqtadir A, Desai CS (1986) Three dimensional analysis of a pilegroup foundation. Int $\mathrm{J}$ Numer Anal Methods Geomech 10(1):41-58

Narsimha Rao S, Ramkrishna VGST (1996) Behaviour of pile supported dolphins in marine clay under lateral loading. J Geotech Eng (ASCE) 122(8):607-612

$\mathrm{Ng}$ CWW, Zhang LM (2001) Three dimensional analysis of performance of laterally loaded sleeved piles in sloping ground. J Geotech Geoenviron 127(6):499-509

Pan JL, Goh ATC, Wong KS, Selby AR (2002) Three-dimensional analysis of single pile response to lateral soil movements. Int J Numer Anal Meth Geomech 26:747-758

Poulos SJ (1971) The stress-strain curve of soils. GEI Internal Report

Pressley JS, Poulos HG (1986) Finite element analysis of mechanisms of pile group behavior. Int $\mathrm{J}$ Numer Anal Meth Geomech 10(1):213-221
Reese LC, Matlock H (1956) Non-dimensional solutions for laterallyloaded piles with soil modulus assumed proportional to depth. In: Proceedings of the 8th Texas conference on soil mechanics and foundation engineering, Austin, TX, pp 1-41

Reese LC, Allen JD, Hargrove JQ (1981) Laterally loaded piles in layered soils. In: P. C. of X ICSMFE (ed) Proceedings of the tenth international conference on soil mechanics and foundations engineering, Stockholm, 2, pp 819-822, June 1981

Reese LC, Wang S-T, Arrellaga JA, Hendrix J (2004) LPILE technical manual: a program for the analysis of piles and drilled shafts under lateral loading, version 7.0, Ensoft, Inc., Austin, TX

Sanjaya Kumar V, Sharma KG, Varadarajan A (2007) Behaviour of a laterally loaded pile. In: Proceedings of the 10th international symposium on numerical models in geomechanics, (NUMOG'07), pp 447-452, April 2007

Sawant VA, Amin NB, Dewaikar DM (1996) Response of a pile to cyclic lateral loads using moment area method. Indian Geotech J 26(4):353-363

Sawant VA, Dewaikar DM (2001) Geometrically non-linear 3-D finite element analysis of a single pile. In: Proceedings of the international conference on computer methods and advances in geomechanics, Balkema, Rotterdam

Spillers WR, Stoll RD (1964) Lateral response of piles. J Soil Mech Eng (ASCE) 90:1-9

Suleiman MT, Raich A, Polson TW, Kingston WJ, Roth M (2010) Measured soil-pile interaction pressures for small diameter laterally loaded pile in loose sand. In: GeoFlorida: advances in analysis, modeling and design conference, Geotechnical Special Publication, Paper 199, pp 1498-1506, February 2010

Trochanis AM, Bielak J, Christiano P (1991) Three-dimensional nonlinear study of piles. J Geotech Eng 117(3):429-447

Wakai A, Gose S, Ugai K (1999) 3-D elasto-plastic finite element analysis of pile foundations subjected to lateral loading. Soil Found 39(1):97-111

Yegian M, Wright SG (1973) Lateral soil resistance-displacement relationships for pile foundations in soft clays. In: Proceedings of the 5th annual offshore technology conference, Houston, TX

Zaman MM, Najjar YM, Muqtadir A (1993) Effects of cap thickness and pile inclination on the response of a pile group by a three dimensional non-linear finite element analysis. Comput Geotech 15(2):65-86

Zhang L (2009) Non-linear analysis of laterally loaded rigid piles in cohesionless soil. Comput Geotech 36(5):718-729 